\title{
QUALIDADE DE SEMENTES DE VIGNA UNGUICULATA CLASSIFICADAS EM DIFERENTES TAMANHOS
}

\author{
Renan Thiago Carneiro Nunes ${ }^{1}$, Ubiratan Oliveira Souza ${ }^{2}$, Arlete da Silva Bandeira ${ }^{1}$, \\ Jerffson Lucas Santos ${ }^{1}$, Otoniel Magalhães Morais ${ }^{3}$, Moniele Ferreira Gomes ${ }^{4}$
}

\footnotetext{
${ }^{1}$ Doutorando em Agronomia (Fitotecnia), Universidade Estadual do Sudoeste da Bahia - UESB, Vitória da Conquista, Bahia, Brasil.

2 Docente do Instituto Federal de Educação, Ciência e Tecnologia Baiano, Campus Bom Jesus da Lapa, Bom Jesus da Lapa, Bahia, Brasil.

${ }^{3}$ Docente do Departamento de Fitotecnia e Zootecnia, Universidade Estadual do Sudoeste da Bahia, Vitória da Conquista, Bahia, Brasil.

${ }^{4}$ Graduando (a) em Engenharia Agronômica na UESB.
}

RESUMO: A análise de sementes é de fundamental importância nos sistemas de produção, pois permite conhecer a real qualidade de um lote e, consequentemente, permitir a tomada de decisões corretas em relação ao manejo cultural, principalmente durante a colheita, processamento e comercialização. O objetivo deste trabalho foi avaliar as diferenças na qualidade fisiológica de semente de Vigna unguiculata cv. BRS Xique-Xique de diferentes tamanhos. As sementes foram passadas por um jogo de peneiras de crivos circulares, sobrepostas, o que possibilitou a separação pela largura. Foram obtidas cinco classes de largura, correspondendo às sementes retidas nas peneiras de números 18, 17, 16, 15, 14 cujos diâmetros dos crivos foram de, respectivamente, 7,14;6,74; 6,35; 5,95 e 5,55 mm. Realizou-se a análise de variância e as médias foram comparadas pelo teste de Tukey ao nível de $5 \%$ de probabilidade. O tamanho das sementes influenciou significativamente na germinação de Vigna unguiculata cv. BRS Xique-Xique.

Palavras-chave: Germinação. Crivos. Feijão caupi.

\section{QUALITY SEED PHYSIOLOGICAL VIGNA UNGUICULATA CLASSIFIED IN DIFFERENT SIZES}

\begin{abstract}
The seed analysis is of fundamental importance in production systems because it allows to know the real quality of a lot and consequently allow making the right decisions in relation to cultural management, especially during the harvesting, processing and marketing. The objective of this study was to evaluate the differences in physiological quality of Vigna unguiculata cv. BRS Xique-Xique seed of different sizes. The seeds were passed through a set of sieves of circular screens, overlapping, allowing the separation by the width. Five classes width were obtained, corresponding to the seeds retained on sieves numbers $18,17,16,15,14$ whose diameters sieves were, respectively, $7.14 ; 6.74 ; 6.35 ; 5.95$ and $5.55 \mathrm{~mm}$. We performed analysis of variance and means were compared by Tukey test at $5 \%$ probability. The seed size significantly influenced the germination of Vigna unguiculata cv. BRS Xique-Xique.
\end{abstract}

Cultura Agronômica, Ilha Solteira, v.26, n.1, p.1-9, 2017 
Key words: Germination. Riddles. Cowpe.

\section{INTRODUÇÃO}

O feijão-caupi (Vigna unguiculata (L.) Walp), também conhecido por feijão macassar ou feijão-de-corda, é uma leguminosa de grande importância socioeconômica, principalmente para as regiões Norte e Nordeste do Brasil, onde constitui um dos componentes da dieta alimentar (TEÓFILO et al., 2008).

O feijão-caupi é excelente fonte de proteínas (23-25\%) e apresenta todos os aminoácidos essenciais, cultivado principalmente para a produção de grãos, secos ou verdes, visando o consumo humano in natura, na forma de conserva ou desidratado (DUTRA et al., 2007). Segundo levantamento da CONAB (2015), a produção brasileira de feijão na safra 2014/2015 foi de 3.338,4 milhões de toneladas, o que manteve o País como o maior produtor mundial do grão.

A utilização de sementes de boa qualidade fisiológica é fator primordial no estabelecimento de qualquer lavoura. Sementes de baixa qualidade, isto é, de potencial de germinação e vigor reduzidos, originam lavouras com baixa população de plantas e em consequência com população inadequada, acarretando sérios prejuízos econômicos (MARCOS FILHO, 2005).

A qualidade fisiológica está relacionada á capacidade da sementes desempenhar suas funções vitais, tais como, longevidade, germinação e vigor. Para Araújo et al. (2004) o processo germinativo e a qualidade dos lotes são afetados diretamente pela desuniformidade das sementes.

Segundo Vanzolini e Nakagawa (2007) sementes menores germinam mais rapidamente, porém as sementes maiores originam plântulas de maior tamanho e massa. Foi verificado por Pádua et al. (2010) a influência do tamanho da semente na qualidade fisiológica e na produtividade da cultura da soja, quando utilizou sementes maiores (peneira 7,0 mm) apresentaram maiores porcentagens de germinação e de vigor.

O tamanho das sementes é definido pelas dimensões, largura e comprimento, sendo aqueles que diferem quanto a largura que podem ser separadas por peneiras crivos circulares e as que diferem quanto a espessura, podem ser separadas pelos crivos oblongos (MARTINELLI-SENEME et al., 2000).

Vários estudos têm verificado eficiência na avaliação da qualidade fisiológica e vigor de sementes através de testes de condutividade elétrica e lixiviação de potássio (VINHALFREITAS et al. 2011; ARAUJO et al., 2011; FAVARATO et al., 2011). Segundo BINOTTI et al. (2008), o teste de condutividade elétrica é um método rápido para a avaliação do vigor das sementes, sendo avaliado da solução de embebição da semente em função direta da quantidade de lixiviados no exsudato do teste, a qual está diretamente relacionada com a integridade das membranas celulares. 
Já, o teste de lixiviação de potássio tem demonstrando ser um índice rápido de avaliação do vigor de sementes de algumas espécies, como feijão-caupi cv. Novaera (ARAUJO NETO et al., 2014). Esse teste tem princípio semelhante ao de condutividade elétrica, baseando-se na integridade das membranas celulares das sementes, com a diferença que no teste de condutividade elétrica, determina-se a quantidade total de íons liberados durante a embebição e, no de lixiviação de potássio, quantifica-se somente o potássio lixiviado na solução, visto que este é o principal íon inorgânico lixiviado pelas sementes durante a embebição (KIKUTI et al., 2008).

Em várias culturas, a classificação de lotes de sementes por tamanho pode afetar a qualidade fisiológica e o vigor inicial das plântulas. Assim, a separação das sementes por classes de tamanho para determinação da qualidade fisiológica tem sido bastante empregada, visando identificar a classe ideal para utilização em diversos manejos de algumas culturas. $\mathrm{O}$ objetivo deste trabalho foi avaliar as diferenças na qualidade física e fisiológica de semente de Vigna unguiculata cv. BRS Xique-Xique de diferentes tamanhos.

\section{MATERIAL E MÉTODOS}

O presente estudo foi conduzido no Laboratório de Tecnologia de Sementes da Universidade Estadual do Sudoeste da Bahia, Campus de Vitória da Conquista (UESB), Campus de Vitória da Conquista, BA, com sementes de feijão-caupi, cultivar BRS XiqueXique, colhidas na safra 2013/2014, produzidas no campus da UESB, localizado a $14^{\circ} 53^{\prime}$ de Latitude sul e $40^{\circ} 48^{\prime}$ de Longitude oeste, com altitude média de 876,91 m.

As sementes de feijão-caupi foram passadas por um jogo de peneiras de crivos circulares, sobrepostas, o que possibilitou a separação pela largura. Foram obtidas cinco classes de largura (tratamentos), correspondendo às sementes retidas nas peneiras de números 18, 17, 16, 15, 14 cujos diâmetros dos crivos foram de, respectivamente, 7,14, $6,74,6,35,5,95$ e 5,55 mm. Em seguida, determinou-se o teor de água, peso de mil sementes e número de sementes por quilo.

Para o teor de água foram utilizadas quatro subamostras de 50 sementes, pelo método padrão da estufa, $105 \pm 3{ }^{\circ} \mathrm{C}$, durante 24 horas e para a determinação do peso de mil sementes foram separadas oito amostras de cem sementes, conforme especificações das Regras para Análise de Sementes (BRASIL, 2009).

Avaliou-se ainda, o número de sementes por quilograma, utilizou-se oito repetições de 100 sementes de cada lote, segundo Oliveira (2007), a partir da seguinte equação: $\mathrm{N}=(1000$ x 1000) / PMS, Onde: $\mathrm{N}=$ número de sementes por kg; PMS = peso de mil sementes em gramas. Para avaliar o efeito do tamanho das sementes na qualidade fisiológica das mesmas, foram analisadas as seguintes variáveis:

Teste de germinação - realizado segundo Brasil (2009), utilizando-se o rolo de papel germitest ${ }^{\circledR}$, em temperatura constante de $25{ }^{\circ} \mathrm{C}$ e quatro repetições de 50 sementes. As avaliações foram realizadas aos cinco e oito dias após a semeadura, e os resultados

Cultura Agronômica, Ilha Solteira, v.26, n.1, p.1-9, 2017 
expressos em percentagem média com base no número de plântulas normais, considerandose como normais as plântulas com as estruturas essenciais perfeitas.

Primeira contagem de germinação - conduzido simultaneamente com o teste de germinação, sendo a porcentagem acumulada de plântulas normais realizada no quinto dia após a montagem do teste.

Condutividade elétrica - executado com quatro subamostras de 50 sementes de cada tratamento, pesadas e colocadas em copos plásticos contendo $75 \mathrm{~mL}$ de água deionizada, esses permaneceram no germinador à temperatura de $25{ }^{\circ} \mathrm{C}$ por $24 \mathrm{~h}$ (VIEIRA; KRZYANOWSKI, 1999). Após esse procedimento, a condutividade elétrica da solução foi aferida e os resultados expressos em $\mu \mathrm{S} . \mathrm{cm}^{-1} \cdot \mathrm{g}^{-1} \mathrm{de}$ sementes.

Lixiviação de potássio $\left(\mathbf{K}^{+}\right)$- Foi avaliada com base na metodologia descrita por Miguel e Marcos filho (2002), utilizou-se quatro subamostras de 50 sementes de cada tratamento, foram pesadas em balança e colocadas em copos plásticos contendo $75 \mathrm{~mL}$ de água deionizada e mantidas no germinador a temperatura de $20{ }^{\circ} \mathrm{C}$ por $24 \mathrm{~h}$. Transcorrido este período, a solução que continha as sementes foi acondicionada em frascos plásticos, identificados e encaminhados para a determinação do íon potássio $\left(\mathrm{K}^{+}\right)$, empregando-se o método de fotometria de chama e os resultados expressos em ppm K.g ${ }^{-1}$ de semente.

O delineamento experimental utilizado foi o inteiramente ao acaso, em quatro repetições para cada tratamento. Os dados obtidos foram submetidos à análise de variância e as médias comparadas pelo teste de Tukey a 5\% de probabilidade por meio do programa estatístico ASSISTAT, versão 7.7 (SILVA, 2014).

\section{RESULTADOS E DISCUSSÃO}

A Tabela 1, expressa os valores referentes ao teor de água, peso de mil sementes e número de sementes/Kg de feijão caupi cv. BRS Xique-Xique de diferentes tamanhos. Verifica-se que não houve diferença significativa entre as classes de peneiras avaliadas para o teor de água das sementes, observa-se que a variação $(1,61 \%)$ está dentro da média estabelecida por Marcos Filho (1999) que é de 1 a 2 pontos percentuais. Para o peso de mil sementes, observa-se que há diferenças significativas entre todas as classes de peneiras analisadas, sementes com maior massa encontram-se entre as sementes das classes de maior tamanho (sementes classificadas nas peneiras de 18 e 17).

Essa diferença de peso com relação aos diversos tamanhos justifica que essas sementes sejam avaliadas quanto à qualidade fisiológica já que, Carvalho e Nakagawa (2012), relatam que as sementes maiores normalmente possuem embriões bem formados e com maiores quantidades de reservas, sendo potencialmente mais vigorosa, quando comparadas com as sementes de menor tamanho.

Cultura Agronômica, Ilha Solteira, v.26, n.1, p.1-9, 2017 
Tabela 1. Teor de água, peso de mil sementes e número de sementes por quilogramas de feijão-caupi (Vigna unguiculata (L.) Walp.), cultivar BRS Xique-Xique, classificadas pela largura. UESB, Vitória da Conquista-BA, 2014.

\begin{tabular}{ccccc}
\hline $\begin{array}{c}\text { Classe de } \\
\text { largura }\end{array}$ & $\begin{array}{c}\text { Crivo da peneira } \\
(\mathrm{mm})\end{array}$ & $\begin{array}{c}\text { Teor de água } \\
(\%)\end{array}$ & $\begin{array}{c}\text { Peso de mil sementes } \\
(\mathrm{g})\end{array}$ & $\begin{array}{c}\mathrm{N}^{\mathrm{o}} \text { de sementes/ } \\
\mathrm{Kg}\end{array}$ \\
\hline Peneira 18 & 7,14 & $11,88 \mathrm{a}$ & $245,52 \mathrm{a}$ & $4.078,00 \mathrm{e}$ \\
Peneira 17 & 6,74 & $12,27 \mathrm{a}$ & $220,37 \mathrm{~b}$ & $4538,00 \mathrm{~d}$ \\
Peneira 16 & 6,35 & $12,58 \mathrm{a}$ & $193,27 \mathrm{c}$ & $5174,00 \mathrm{c}$ \\
Peneira 15 & 5,95 & $11,56 \mathrm{a}$ & $163,37 \mathrm{~d}$ & $6121,00 \mathrm{~b}$ \\
Peneira 14 & 5,55 & $13,17 \mathrm{a}$ & $138,05 \mathrm{e}$ & $7244,00 \mathrm{a}$ \\
\hline CV $(\%)$ & - & 11,91 & 1,76 & 0,07 \\
\hline
\end{tabular}

Médias seguidas pelas mesmas letras não diferem pelo teste de Tukey a 5\% de probabilidade.

Araujo Neto et al. (2014), analisando a germinação e vigor de sementes de diferentes tamanhos de feijão-caupi cv. Novaera, também verificaram que o peso de mil sementes aumentou proporcionalmente com o tamanho da semente.

Já em relação ao número de semente por quilograma, as sementes classificadas na peneira 18, apresentou um menor número por quilograma $(4.078,00)$, diferindo estatisticamente das demais classes de peneiras analisadas. A peneira (14) foi a que apresentou um maior número de sementes por quilograma (7.244,00). Assim, quanto maior for o peso das sementes menor será o número de sementes por quilograma e vice-versa.

Esta relação tem importância prática do ponto de vista econômico, pois o produtor busca a obtenção de sementes bem formadas, consequentemente mais pesadas, aumentando seu lucro/produção. Uma vez que, a tendência do mercado é a comercialização por número e não mais por peso de sementes.

Tabela 2. Germinação e primeira contagem da germinação de sementes de feijão caupi (Vigna unguiculata (L.) Walp.), cultivar BRS Xique-Xique, classificadas pela largura. UESB, Vitória da Conquista-BA, 2014.

\begin{tabular}{lccc} 
Classe de largura & Crivo da peneira $(\mathrm{mm})$ & $\begin{array}{c}\text { Germinação } \\
(\%)\end{array}$ & $\begin{array}{c}\text { Primeira contagem } \\
(\%)\end{array}$ \\
\hline Peneira 18 & 7,14 & $100 \mathrm{a}$ & $89 \mathrm{a}$ \\
Peneira 17 & 6,74 & $98 \mathrm{a}$ & $78 \mathrm{~b}$ \\
Peneira 16 & 6,35 & $95 \mathrm{ab}$ & $83 \mathrm{~b}$ \\
Peneira 15 & 5,95 & $90 \mathrm{ab}$ & $71 \mathrm{c}$ \\
Peneira 14 & 5,55 & $87 \mathrm{~b}$ & $70 \mathrm{c}$ \\
\hline CV $(\%)$ & - & 4,39 & 3,33 \\
\hline
\end{tabular}

Médias seguidas pelas mesmas letras não diferem pelo teste de Tukey a 5\% de probabilidade.

Cultura Agronômica, Ilha Solteira, v.26, n.1, p.1-9, 2017 
Nota-se, que houve diferença significativa entre as classes de larguras analisadas para a germinação e primeira contagem das sementes (Tabela 2), sendo a classe de peneira 14 a que apresentou menor resultado de germinação (87\%), já para primeira contagem de germinação a as classes de peneiras 15 e 14 foram as que apresentaram menor porcentagem de germinação (71 e $70 \%$ ), diferindo das peneiras de crivo 18, 17 e 16, porém os lotes das sementes em estudo satisfazem o padrão estabelecido para comercialização, com germinação superior a 80\% (Brasil, 2009).

Pádua et al. (2010), relatam que sementes de soja de maior tamanho apresentaram desempenho superior nos testes de germinação, o mesmo foi observado no presente estudo. Enquanto, Fantinatti et al., (2002), encontraram diferenças significativas quando compararam a emergência das plântulas em campo de feijão ( $P$. vulgaris) de diferentes densidades, verificando a influencia na uniformidade do estande das plantas.

De acordo com Carvalho e Nakagawa (2012), o tamanho da semente é um dos fatores que podem influenciar na germinação e no vigor das sementes. As sementes maiores são as que foram mais bem nutridas durante seu desenvolvimento e que normalmente possuem embriões bem formados e com maiores quantidades de reservas, logo num mesmo lote, as sementes maiores, potencialmente, apresentam maior poder germinativo que as sementes menores.

Em estudo realizado por Pádua et al. (2010), verificaram influência do tamanho da semente de três cultivares de soja (Glycine max) na qualidade fisiológica da mesma, demonstrando que sementes maiores (peneira 7,0 $\mathrm{mm}$ ) foram mais vigorosas do que as sementes menores (peneira 6,0 $\mathrm{mm}$ ).

Os dados referentes à condutividade elétrica e a lixiviação potássio de sementes de feijão-caupi (Vigna unguiculata (L.) Walp.), estão apresentados na Tabela 3.

Tabela 3. Condutividade elétrica e lixiviação de potássio de sementes de feijão-caupi (Vigna unguiculata (L.) Walp.), cultivar BRS Xique-Xique, classificadas pela largura.

\begin{tabular}{cccc}
\hline Classe de largura & $\begin{array}{c}\text { Crivo da peneira } \\
(\mathrm{mm})\end{array}$ & $\begin{array}{c}\text { Condutividade elétrica } \\
\left(\mu \mathrm{Sm}^{-1} \mathrm{~g}^{-1}\right)\end{array}$ & $\begin{array}{c}\text { Lixiviação de potássio } \\
\left(\mathrm{ppm} \mathrm{K}^{+} \cdot \mathrm{g}^{-1}\right)\end{array}$ \\
\hline Peneira 18 & 7,14 & $166,42 \mathrm{a}$ & $4663,88 \mathrm{a}$ \\
Peneira 17 & 6,74 & $174,80 \mathrm{a}$ & $3163,40 \mathrm{~b}$ \\
Peneira 16 & 6,35 & $184,46 \mathrm{a}$ & $2449,40 \mathrm{c}$ \\
Peneira 15 & 5,95 & $152,33 \mathrm{a}$ & $2365,27 \mathrm{c}$ \\
Peneira 14 & 5,55 & $235,46 \mathrm{a}$ & $1796,47 \mathrm{~d}$ \\
\hline CV $(\%)$ & - & 22,31 & 6,83
\end{tabular}

Médias seguidas pelas mesmas letras não diferem pelo teste de Tukey a 5\% de probabilidade.

Em relação à condutividade elétrica das sementes de feijão-caupi, cv. BRS XiqueXique, nota-se que não houve diferença significativa entre as classes de peneiras avaliadas. Entretanto, as sementes classificadas na peneira $14\left(235,46 \mu \mathrm{S} \mathrm{cm} \mathrm{cm}^{-1} \mathrm{~g}^{-1}\right)$, apresentaram 
maior valor absoluto em relação a condutividade elétrica das demais classes de sementes, indicando assim, menor vigor em relação as outras classes de peneiras estudadas.

A menor quantidade de lixiviados na solução de embebição das sementes indica melhor estruturação das membranas e, consequentemente, maior vigor. De acordo com Marcos Filho (2005), o teste de condutividade elétrica tem se mostrado eficiente para a avaliação do vigor de sementes de várias espécies. Dias et al. (1998), concluíram que o teste de condutividade elétrica foi eficiente para a avaliação do potencial fisiológico das sementes de feijão-de-vagem e quiabo.

As sementes retidas na peneira $18(7,14 \mathrm{~mm})$, apresentaram maior lixiviação de potássio $\left(4.663,88 \mathrm{ppm} \mathrm{K}^{+} \cdot \mathrm{g}^{-1}\right)$, Já as sementes retidas na peneira (14), apresentaram menor lixiviação de potássio $\left(1.796,47 \mathrm{ppm} \mathrm{K}^{+} \cdot \mathrm{g}^{-1}\right)$, revelando assim pelo teste de lixiviação de potássio que as sementes retidas nas classes de peneiras menor, apresentaram uma menor liberação de íons de potássio, fato importante pois, quanto menor a liberação de íons, maior a integridade das membranas celulares, consequentemente, maior vigor as sementes irão apresentar. No entanto, no presente estudo não foi possível correlacionar que as sementes que apresentassem uma menor lixiviação de $\mathrm{K}^{+}$, proporcionariam melhor qualidade e capacidade germinativa.

Queiroga e Parra (1989), destacaram a influência do peso das sementes sobre a lixiviação de potássio, mostrando que as mais pesadas apresentaram valores mais altos de lixiviação. Já Woodstock et al., (1985) trabalhando com sementes de algodão observaram a deterioração das membranas através da microscopia eletrônica, ressaltando, que a lixiviação de íons individuais, como o $\mathrm{K}^{+} \mathrm{e} \mathrm{Ca}^{2+}$, foram os melhores indicadores da qualidade das sementes.

\section{CONCLUSÃO}

O tamanho das sementes influenciou significativamente a qualidade física e fisiológica do Vigna unguiculata cv. BRS Xique-Xique.

A utilização do teste de lixiviação de potássio em diferentes tamanhos das sementes não foi eficiente na identificação da melhor qualidade fisiológica dos lotes.

\section{REFERÊNCIAS BIBLIOGRÁFICAS}

ARAUJO NETO, A. C.; NUNES, R. T. C.; ROCHA, P. A. ÁVILA, J. S.; MORAIS, O. M. Germinação e vigor de sementes de feijão-caupi (Vigna unguiculata (L.) Walp.) de diferentes tamanhos. Revista Verde, Mossoró, v. 9, n. 2, p.71-75, 2014.

ARAUJO, R. F.; ZONTA; J. B.; ARAUJO, E. F.; HEBERLE, E.; ZONTA, F. M. G. Teste de condutividade elétrica para sementes de feijão-mungo-verde. Revista Brasileira de Sementes, Londrina, v. 33 n. 1, p.123-130, 2011.

Cultura Agronômica, Ilha Solteira, v.26, n.1, p.1-9, 2017 
ARAUJO, E. F.; MEIRELES, R. C.; REIS, L. S.; MAURI, A. L.; DAVI, A. M. S. S. Uso de peneiras e mesa gravitacional na classificação e na qualidade de sementes de cafeeiro (Coffea arábica L.). Revista Brasileira de Armazenamento. Viçosa, v. 25, n. 8, p.24-28, 2004.

BINOTTI, F. F. S.; HAGA, K. I.; CARDOSO, E. D.; ALVES, C. Z.; SÁ, M. E.; ARF, O. Efeito do período de envelhecimento acelerado no teste de condutividade elétrica e na qualidade fisiológica de sementes de feijão. Acta Scientiarum Agronomy, Maringá, v. 30, n. 2, p.247-254, 2008.

BRASIL. Ministério da Agricultura, Pecuária e Abastecimento. Regras para Análise de Sementes. Secretária de Defesa Agropecuária. Brasília: MAPA/ACS, 2009. 395 p.

CARVALHO, N. M.; NAKAGAWA, J. Sementes: ciência, tecnologia e produção. 5. ed. Jaboticabal: FUNEP, 2012. 590 p.

CONAB. Acompanhamento da safra Brasileira grãos: Safra 2014/15, Quarto Levantamento, Brasília, v. 2, n. 4, p.1-90, 2015.

DIAS, D. C. F. S.; VIEIRA, A. N.; BHÉRING, M. C. Condutividade elétrica e lixiviação de potássio para avaliação do vigor de sementes de hortaliças: feijão-de-vagem e quiabo. Revista Brasileira de Sementes, Londrina, v. 20, n. 2, p.408-413, 1998.

DUTRA, A. S.; TEÓFILO, E. M.; MEDEIROS FILHO, S.; DIAS, F. T. C. Qualidade fisiológica de sementes de feijão caupi em quatro regiões do estado do Ceará. Revista Brasileira de Sementes, Londrina, v. 29, n. 2, p.111-116, 2007.

FANTINATTI, J. B.; HONÓRIO, S. L.; RAZERA, L. F. Qualidade de sementes de feijão de diversas densidades obtidas na mesa gravitacional. Revista Brasileira de Sementes, Londrina, v. 24, n. 1, p.24-32, 2002.

FAVARATO, L. F.; ROCHA, V. S.; ESPINDULA, M. C.; SOUZA, M. A.; PAULA, G. S. Teste de lixiviação de potássio para avaliação da qualidade em sementes de trigo. Revista Brasileira de Ciências Agrárias, Recife, v. 6, n. 4, p.670-674, 2011.

KIKUTI, H.; MEDINA, P. F.; KIKUTI, A. L. P.; RAMOS, N. P. Teste de lixiviação de potássio para avaliação do vigor de sementes de amendoim. Revista Brasileira de Sementes, Londrina, v. 30, n. 1, p.10-18, 2008.

MARCOS FILHO, J. Fisiologia de sementes de espécies cultivadas. Jaboticabal: Funep, 2005. $546 \mathrm{p}$.

MARTINELLI-SENEME, A.; MARTINS, C. V. C.; NAKAGAWA, J. Germinação de milho cv. AL-34 em função do tamanho da semente e do potencial hídrico do substrato. Revista Brasileira de Sementes, Londrina, v. 22, n. 2, p.131-138, 2000.

MARCOS FILHO, J. Teste de envelhecimento acelerado. In: KRZYZANOWSKI, F. C.; VIEIRA, R. D.; FRANÇA NETO, J. B. (Ed.) Vigor de sementes: conceitos e testes. Londrina: ABRATES, 1999. cap. 3, p.1-24.

Cultura Agronômica, Ilha Solteira, v.26, n.1, p.1-9, 2017 
MIGUEL, M. V. C.; MARCOS FILHO, J. Potassium leakage and maize seed physiological potential. Scientia Agricola, Piracicaba, v. 59, n. 2, p.315-319, 2002.

OLIVEIRA, O. S. Tecnologia de sementes florestais. Curitiba: Imprensa Universitária, 2007. $185 \mathrm{p}$.

PÁDUA, G. P.; ZITO, R. K.; ARANTES, N. E.; FRANÇA NETO, J. B. Influência do tamanho da semente na qualidade fisiológica e na produtividade da cultura da soja. Revista Brasileira de Sementes, Londrina, v. 32, n. 3, p.9-16, 2010.

QUEIROGA, V. P. PARRA, N. R. Análises dos eletrólitos nos exsudatos das sementes de girassol (Helianthus anuus L.). In: CONGRESSO BRASILEIRO DE SEMENTES, 6., 1989, Brasília. Resumos. Brasília, ABRATES, 1989. p. 66.

SILVA, F. A. S. ASSISTAT: Versão 7.7 beta. DEAG-CTRN-UFCG - Atualizado em 01 de abril de 2014. Disponível em: http://www.assistat.com/. Acesso em: 15 nov 2015.

TEÓFILO, E. M.; DUTRA, A. S.; PITIMBEIRA, J. B.; DIAS, F. T. C.; BARBOSA, F. S. Potencial fisiológicos de sementes de feijão caupi produzidas em duas regiões do estado do Ceará. Revista Ciência Agronômica, Fortaleza, v. 39, n. 3, p.443-448, 2008.

VANZOLINI, S.; NAKAGAWA, J. Testes de vigor baseados no desempenho de plântulas. Informativo ABRATES, Londrina, v. 17, n. 1-3, p.76-83, 2007.

VIEIRA, R. D.; KRZYZANOWSKI, F. C. Teste de condutividade elétrica. In: Krzyzanowski, F.C.; VIEIRA, R. D.; FRANÇA NETO, J. B. (Ed.). Vigor de sementes: conceitos e testes. Londrina: ABRATES, 1999. cap. 4, p.1-26.

VINHAL-FREITAS, I. C.; NUNES JUNIOR, J. E. G.; SEGUNDO, J. P.; VILARINHO, M. S. Germinação e vigor de sementes de soja classificadas em diferentes tamanhos. Agropecuária Técnica, Areia, v. 32, n. 1, p.108-114, 2011.

WOODSTOCK, L. W.; FURMAN, K.; LEFFLER, H. R. Relationship between weathering deterioration and germination, respiratory metabolism, and mineral leaching from cottonseeds. Crop Science, Madison, v. 25, n. 3, p.459-466, 1985. 